\title{
MODIFICATION OF POWDER MATERIAL BY COMPACTION PROCESSING
}

\author{
Peter Peciar*, Oliver Macho, Maroš Eckert, Juraj Kabát, \\ L'udmila Gabrišová, Peter Kotora, Roman Fekete, Marián Peciar
}

\author{
Slovak University of Technology in Bratislava, Faculty of Mechanical Engineering, Institute of Process \\ Engineering, Námestie Slobody 17, 812 31, Bratislava, Slovakia \\ * corresponding author: peter.peciar@stuba.sk
}

\begin{abstract}
There are different criteria for assessing the appropriateness of an agglomeration technology in the deployment processing of dry, fine and dirty dust burdening in the communal and working environment. Besides the benefit of the environment components, the agglomeration technology offers the possibility of re-processing the material as the primary raw material within a wide range of industries. Preliminary tests have shown that the compressed material remains in the memory from the previous compression. For returning the already processed material into a primary production, it is essential that it is reformed without the need for additional materials, a requirement that can be problematic. This article deals with the modification of a powder material (powder dust from the manufacture of friction components) and the investigation of its properties before and after the compaction processing.
\end{abstract}

KEYWORDS: powder material; compaction; agglomerate strength; distribution characteristic; microscopic analysis; compressibility.

\section{INTRODUCTION}

An illustrative application of these environmental technologies is, for example, the disposal of a dust in the manufacture of friction components, such as brake linings for cars [1, 2]. The aim was to effectively recover the dust, usually stored in landfills, in a form suitable for its effective reuse in the production process or as a material and energy recycling, the direct consequence of which is savings on the landfill storage. If the recycled material contains new element, on its return to the production process, the inhomogeneities of the material could affect the final product quality, thus having a significant impact on the vibration and noise effects of the brake components [3, 4]. Therefore, the research was focused on procedures for processing dust powder into a compact dust-free format in which it would not be necessary to use additional agglomeration materials. Using a special technology, it is possible to transform the dust waste into agglomerates, which then makes possible further treatment with the properties of the examined material unchanged. Since a high pressure is necessary for the agglomeration of the dust from the production of brake linings, the technology of a dry high pressure continuous compaction has to be considered [5].

\section{THEORY OF COMPACTION}

One of the technological processes of the powder processing is the roll press compaction. This is a continuous process of a high-pressure compression of a particulate material between two rotating rolls, with a compacted strip as the final product. In dependence on the shape of the rolls, it is possible to create various types of product. If the compactor rolls are smooth, a continuous ribbon comes out of the compactor and is then divided into smaller pieces. If the compactor rolls are toothed, products in the form of profiled strips or briquettes are obtained by setting the desired gaps between the rollers. Compaction is a process in which the particulate material is processed without additives or with the addition of only a very small amount of additive (e.g., agglomeration liquid or powder).

ne of the most acknowledged authors working in the particulate material compaction is J. R. Johanson. In his articles [6, 7], the compaction process is described. In [8, the problem of the wear of the rolls during compaction is dealt with. It is recommended, whenever possible, to use the roughened surface of the roller with the roller gap kept as large as the product quality allows. In [9, 10], the author describes the issue of air contained in the particulate material, showing the relationship necessary for an approximate calculation of the maximum pressure in the compacted strip. Critical compaction pressure is the function of the rotation speed of the rolls, cylinder diameter, the compressibility of the material, and the strength of the product. The author also deals with [11] the possibilities for reducing the air content and general improvement in the process of the compaction. The result of the study is the use of screw conveyors to transport the material between the compactor rollers with the goal of maintaining a constant gap between the rolls. A recommended step is a mixing of the raw material and the compacted recycled material in order to reduce the air content in the compacted strip.

The mathematical model proposed by Johanson shows the relationship between material properties, 


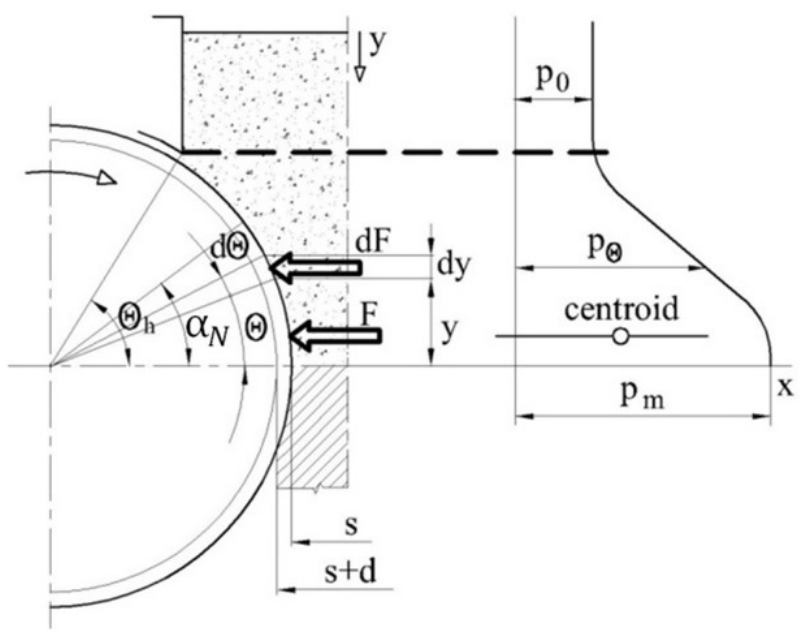

FiguRE 1. Forces balance in the compression zone of the compacting process $[14$.

dimensions and compactor operating conditions. This model may be expressed as the force between the rolls necessary to achieve the desired compression pressure for the material. It is assumed that the material is isotropic, compressible, and also behaves according to the effective flow function as proposed by Jenike and Schield [12. The effective flow function for planar tightness, which is taken into account in the roller compaction, is described by the effective internal friction angle.

In addition to Johanson, several authors such as Komarek [13] have worked on the compaction process. While the approaches of the various authors of the theories may differ, it is generally agreed on that different areas exist in the pressing zone of the compactor rollers. Most frequently, the course of compacting is divided into three areas - the slip area, the pressing area and the area of expansion. In the first area, the slipping of the material over the surface of the rollers takes place. In the second area, the material is wedged between the rollers, and is drawn into the gap between them at the same time as it is being pressed. In the third area, expansion occurs due to the elastic deformation of the compressed material in the area of the maximum compression pressure $p_{m}$ (Fig. 1).

It was Johansson who described the compaction of a particulate material through a two-roll compactor by the so-called wedge angle $\alpha_{N}$. This angle separates the slip area and the area of compression. In the slip area, there is a mutual movement between the surface and the material in the zone over the wedge angle. The material is acted on by its own weight, by the force effect of the screw during the forced feeding and to a small extent by the shear stress from the rollers through which the material is dragged into the area between the rolls. In this zone, the particles of the material change position and a displacement of a substantial part of the air contained in the material occurs. In the area of the pressing zone under the angle wedge, the material on the surface of the rolls

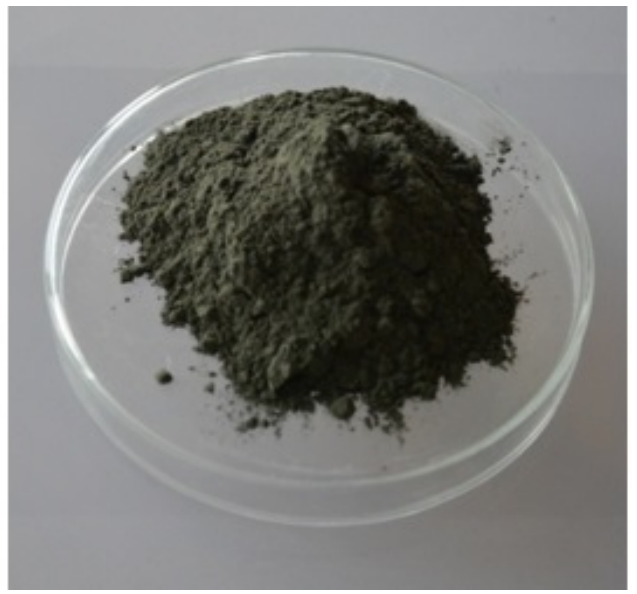

Figure 2. Dust from brake lining production.

moves at the same speed as the surface speed of the rolls. The effects of the wall friction are progressively reduced, and on the contrary, the normal components of the stress from the rolls begin to work on the material. In this area, the particles of the material deform and the material becomes compact.

For the zone over the wedge angle, it is possible to calculate the pressure conditions by the means of the bulk materials mechanics. For the zone under the wedge angle, pressure ratios are derived from the strain curve. Stress distribution between the rollers over the wedge angle can be calculated by combining the equation of the particulate material balance element and the limit state equation, provided that the boundary conditions are given [15, 16], and, in the case of the stress distribution under the wedge angle, the volume strain dependency can be applied.

\section{COMPACTION OF DUST FROM BRAKE LINING PRODUCTION}

The material for the manufacture and testing of samples was a waste dust from the production of brake linings (Fig. 2). For compacting, an experimental compactor, designed and manufactured at the Institute of Process Engineering, Faculty of Mechanical Engineering, Slovak University of Technology in Bratislava, was used. The product of the material compaction was a continuous strip (Fig. 5). The compaction process ran with two different rotations of the compactor rolls, which represented various product mass flows $\left(1.35 \mathrm{rpm}-22 \mathrm{~kg} \mathrm{~h}^{-1}, 6.75 \mathrm{rpm}-110 \mathrm{~kg} \mathrm{~h}^{-1}\right)$. In the process of compaction, the wedge angle was found according to the relation by (1), where $\alpha_{N}$ is the wedge angle, $s$ is the gap between the rolls, $D$ is the diameter of the compactor rolls, $\rho$ is the bulk density of the agglomerates and $\rho_{1}$ is the material density:

$$
\alpha_{N}=\arccos \left(1-\frac{s}{D}\left(\frac{\rho}{\rho_{1}}-1\right)\right) .
$$

An average wedge angle of $9.78^{\circ}$ was found from the experiments. 


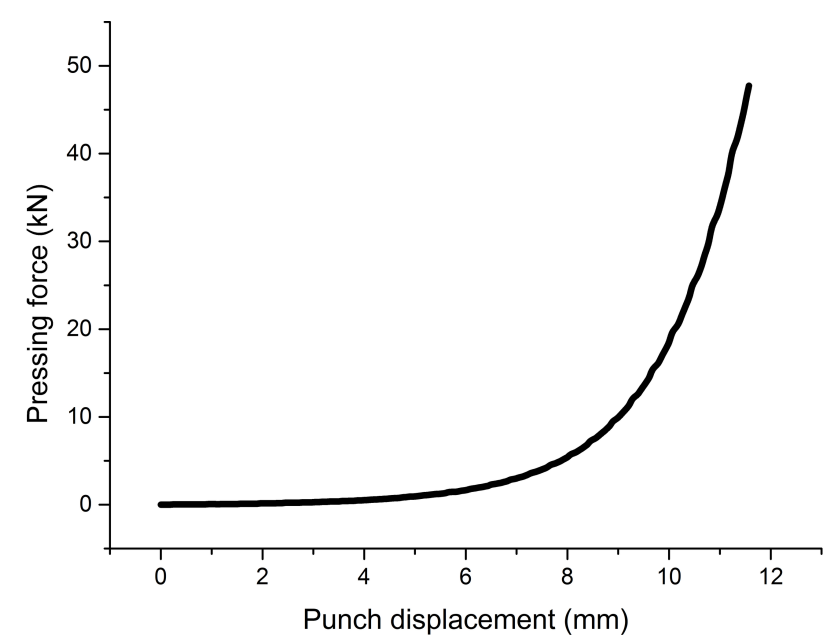

Figure 3. Course of single-axis compactibility test.

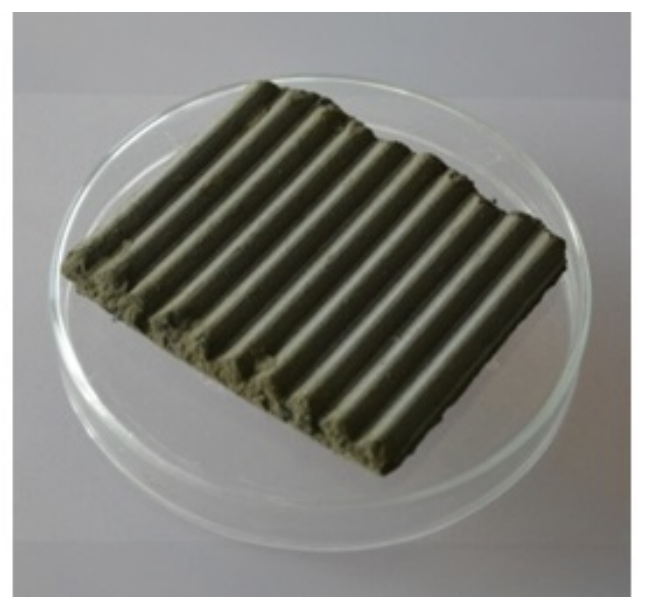

FiguRE 5. Profiled strip of experimental material from compacting process.

\section{Single-AXIS COMPACTIBILITY}

Before the actual process of compacting, it was necessary to verify the compatibility of the test material in an oedometer, from which its capacity for compacting was discovered. The course of the single-axis compressibility test is shown in Figure 3, with a modified version, which adds a logarithm of stress ratio $\ln \left(\frac{\sigma}{\sigma_{0}}\right)$ and a logaritm of densities ratio $\ln \left(\frac{\rho}{\rho_{0}}\right)$ to the dependency (Fig. 4) by (2), where $\sigma$ is normal stress, $\sigma_{0}$ is initial normal stress, $\rho$ is tablet bulk density, $\rho_{0}$ is the initial bulk density of powder and $K$ is the Johanson compressibility factor:

$$
\ln \frac{\sigma}{\sigma_{0}}=K \ln \frac{\rho}{\rho_{0}}
$$

By means of this modification, it was possible to assess the behaviour of the test material during the single-axis compaction, wherein this material behaved accordingly to the compaction theory in line with Johanson; by means of the mathematical analysis, a compressibility factor of 8,634 was found. The test material is well-compressible and suitable for the compaction in a roll compactor. If the compressibility

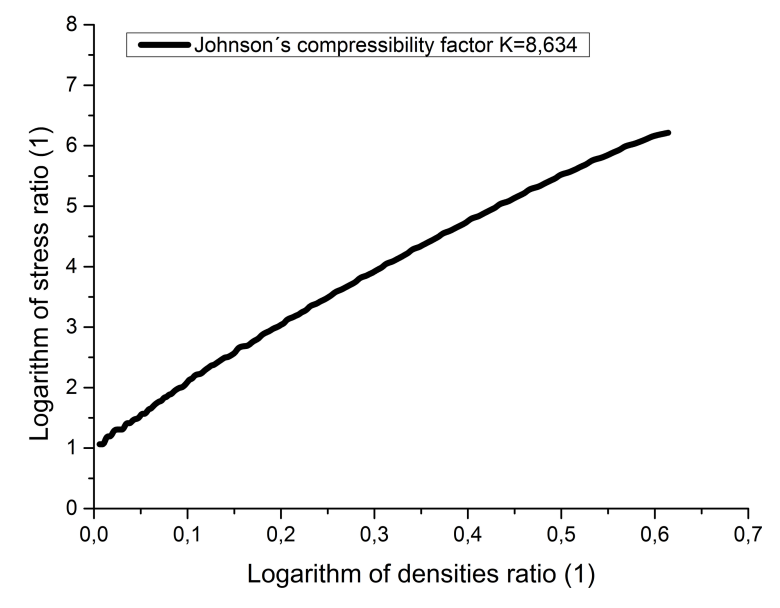

Figure 4. Course of single-axis compactibility test according to Johanson.

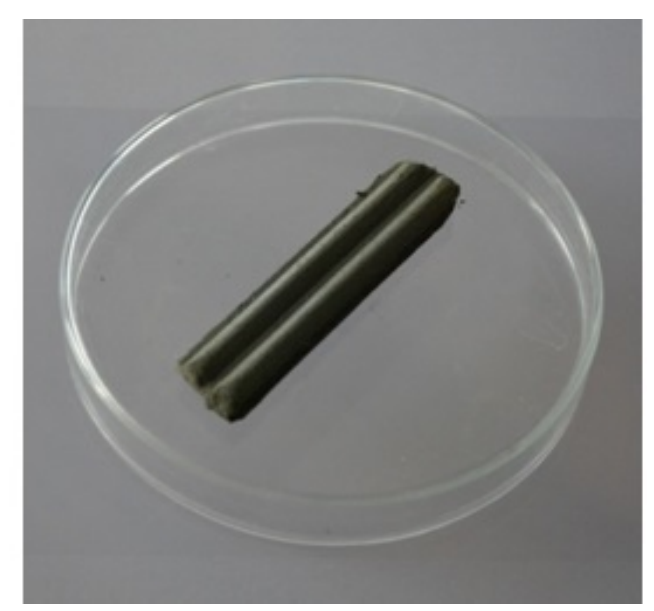

Figure 6. Sample for testing of strength against breaking and disintegrating.

factor is equal to the value 1 , the compressibility of the sample is linear throughout the whole course of the compaction of the samples. The higher the factor, the less linear is the compressibility of the sample throughout the course. If the value of the compression force does not sufficiently exceed the required value, a sufficient sample compression does not occur. Although an exact definition of the Johanson compressibility factor is not possible, the higher this number is (tens, hundreds), the more problematic is the compaction process.

\section{Agglomerate strength IN DEPENDENCE ON COMPACTION PROCESS PARAMETERS}

Before making the agglomerates in their final form, it was necessary to perform an experimental measuring, by which the forces necessary to break and disconnect the compacted test samples (Fig. 6), so that they would be suitable for later material recycling, were examined. The test samples were created from a continuous strip (Fig. 5) at various mass flows 


\section{Strength required for the breaking of the sample}

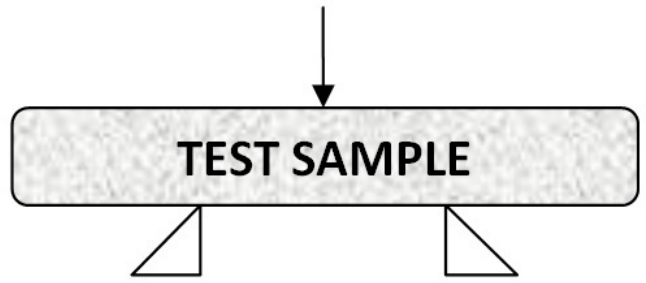

FIGURE 7. Physical principle of testing sample against breaking.

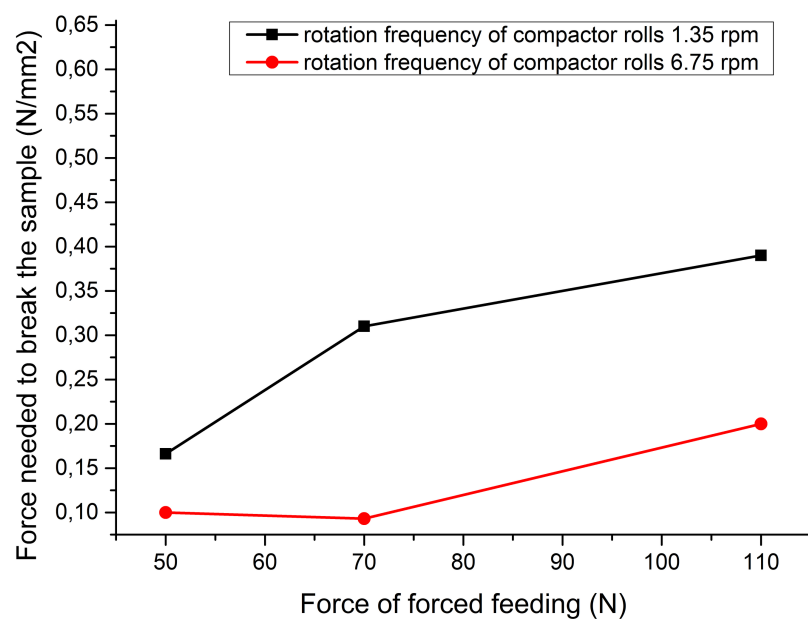

Figure 9. Influence of strength of forced feeding on the strength required to break the test sample at constant rotation of the compactor rolls [17].

(compactor's output) and with different operating parameters.

The influence of the composition and operating parameters on the strength of the compacting material was examined. The principle for measuring the strength against breaking and disintegration is shown in Figures 7 and 8 The complete process, the composition, and the parameters examined in the creating of the samples, as well as the testing of the strength against breaking and disintegrating, are shown in [17. The strength required for the breaking of the samples depends mainly on the rotational frequency of the compactor's rolls and the strength of the forced feeding of the material between the rolls. The dependency is shown in Figure 9 The strength necessary for the disintegration of the samples was dependent on the rotational frequency of the compactor's rolls and the strength of the forced feeding of the material between the rolls, as it is illustrated in Figure 10. The result of the investigation of the agglomerate strength was the fact that compacting of the waste powder was possible, and the product thus produced, in the form of compacted material, satisfies the needs of the transportation in terms of strength, without a further generation of a powder share.

\section{Strength required for the \\ breaking of the sample}

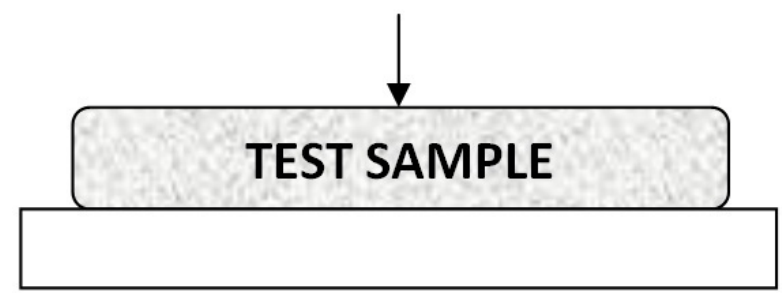

FIGURE 8. Physical principle of testing sample against disintegration.

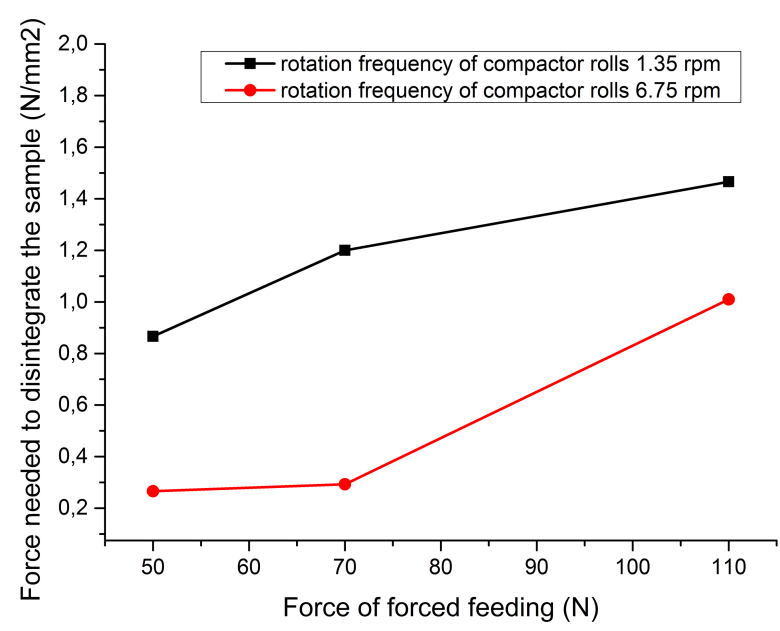

FiguRE 10. Influence of strength of forced feeding on the strength required to disintegrate the test sample at constant rotation of the compactor rolls 17 .

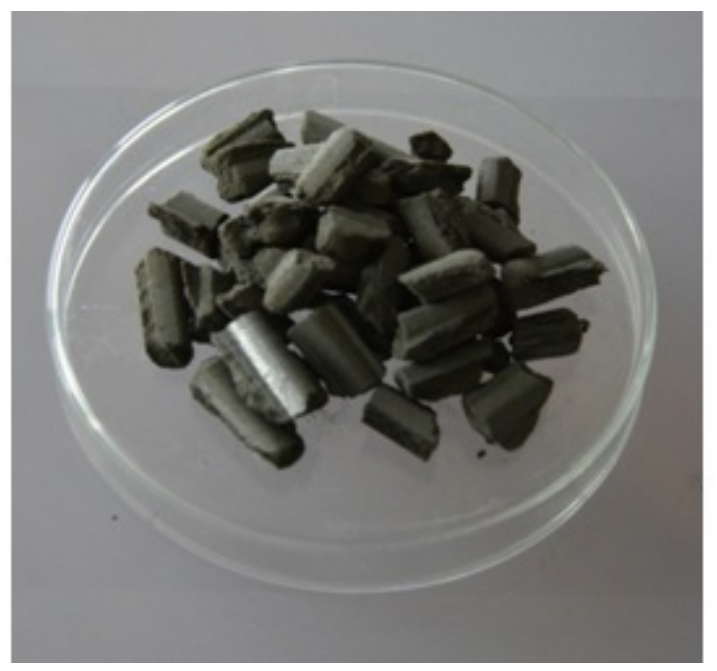

FiguRE 11. Final product.

After the strength characteristics experiments, it was necessary to disintegrate (granulate) the compacted strip (Fig. 5). In order to reduce a formation of powder, a knife mill without a sieve and with a low rotation frequency of the knives was used. The agglomerates created by this disintegration are illustrated in Figure 11 


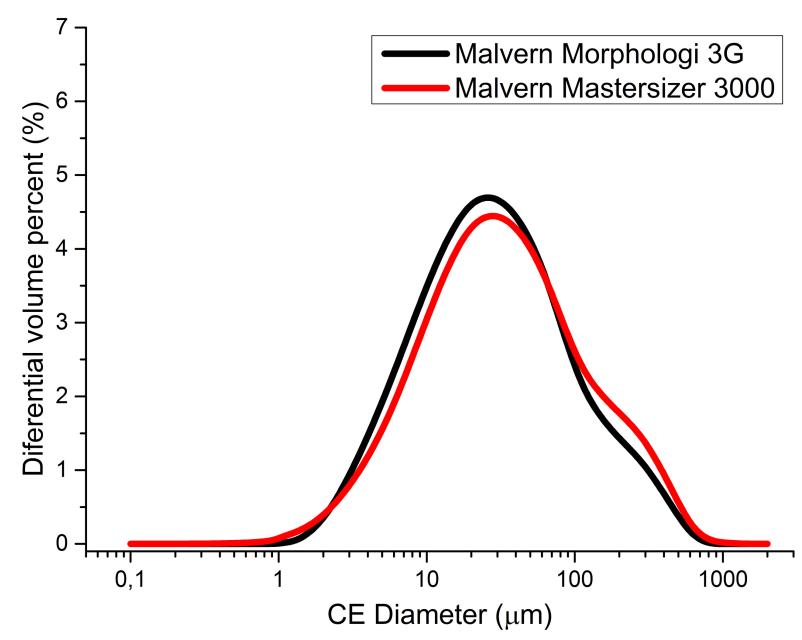

FiguRE 12. Distribution characteristic of pure raw material created on Malvern Morphologi 3G and Malvern Mastersizer 3000 equipment.

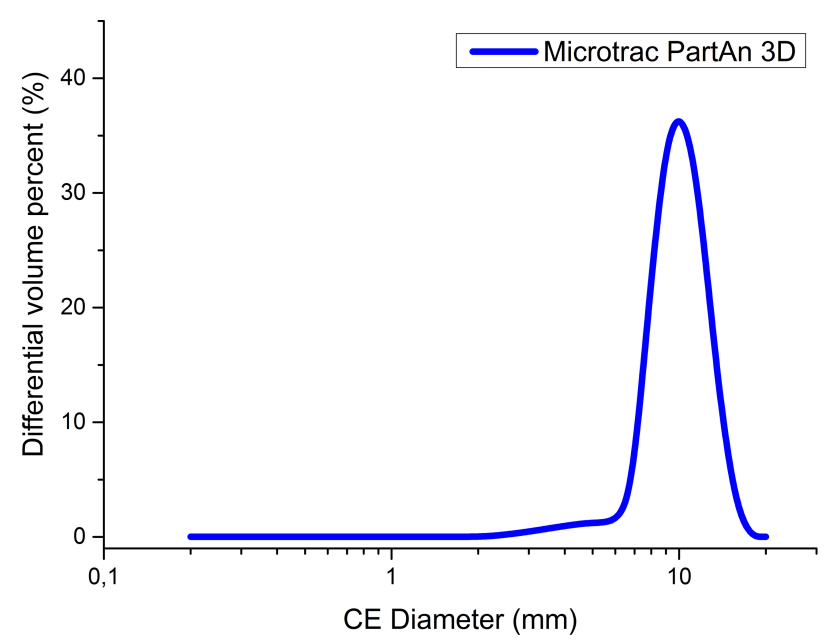

FiguRE 13. Distribution characteristic of produced agglomerate measured on Microtrac PartAN equipment.

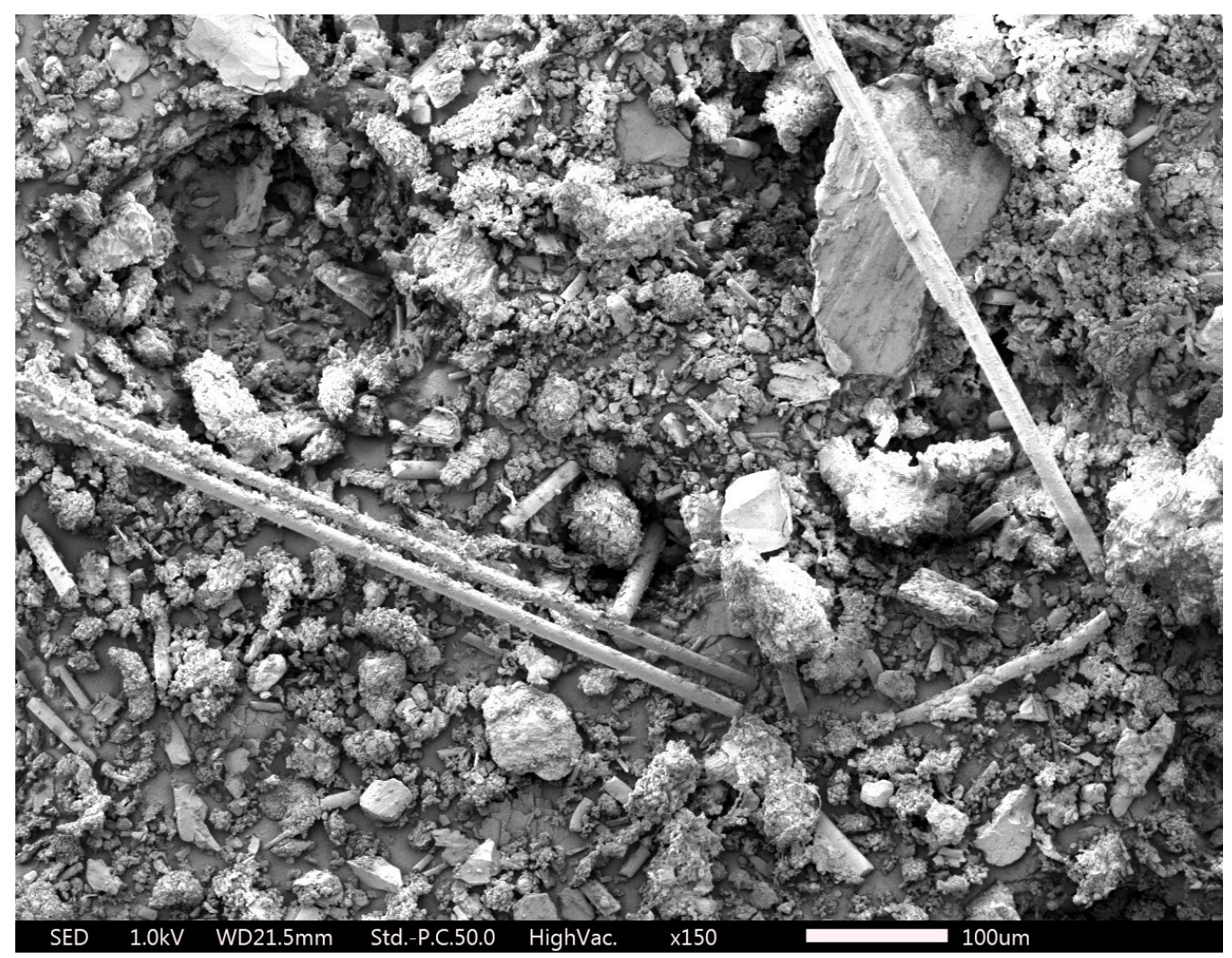

Figure 14. Shot of brake powder at 150-times enlargement, made by a JoelR Scanning electron microscope (SED-1.0kV-WD21.5mm-Std.P.C.50.0-HighVac-x150).

\section{Distribution CHARACTERISTICS OF PURE RAW MATERIAL AND CREATED PRODUCT}

In the processing of powder materials, the quality and size of the products are strongly determined by, among other things, the distribution characteristics of the processed raw material. Every type of particles (i.e., small - powder, large, fibrous) needs a different type of compaction. Small (powder) particles, large or fibrous for example, compact differently.
The requirement from the producer of the powder from the manufacture of brake linings was to achieve high quality non-powdery products. As it is usual with such technologies, it is essential to know the mechanical-physical properties of the processed material as much as possible. The basis is a detailed fractional analysis. The distribution characteristic of the pure raw material was prepared on Malvern Morphologi 3G and Malvern Mastersizer 3000 equipment (Fig. 12). While the measuring on the Malvern Morphologi was prepared on the basis of the static 


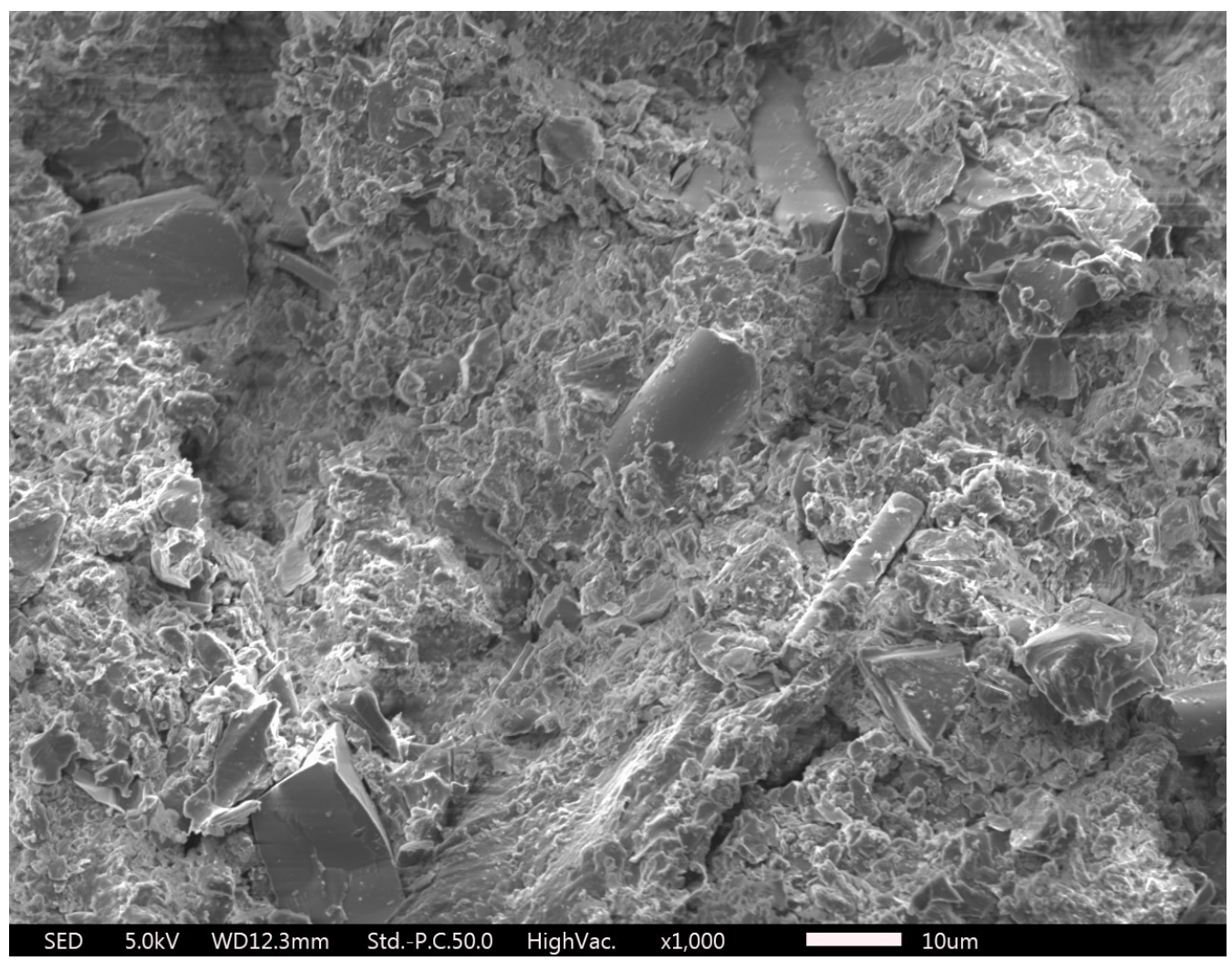

FIgURE 15. Shot of the agglomerate at 1000-times enlargement, made by a JoelR Scanning electron microscope (SED-5.0kV-WD12.3mm-Std.P.C.50.0-HighVac-x1000).

pictorial image analysis of their volume, measuring on the Malvern Mastersizer 3000 was on the basis of a dynamic pictorial analysis of their volume [18 20]. The results of both analyses are in excellent conformity (Malvern Mastersizer $3000-\mathrm{DV}(10)=6.65 \mu \mathrm{m}$, $\mathrm{DV}(50)=27.8 \mu \mathrm{m}, \mathrm{DV}(90)=151 \mu \mathrm{m})$. The distribution characteristic of the agglomerate produced was, due to the size of the particles, performed on a Microtrac PartAN 3D (Fig. 13) analyzer of the picture of the particles. The particles falling from the vibration hopper were recorded by the means of a high-speed camera which took pictures of the motion of the falling particles. On the basis of the series of pictures, a complete 3D picture of the individual agglomerates was prepared, as was the consequent cumulative distribution characteristic on the basis of their volume. The characteristic dimension DV(50) from the analysis of the agglomerates was $11.24 \mathrm{~mm}$.

\section{MiCROSCOPIC ANALYSIS OF PURE RAW MATERIAL FROM MANUFACTURED PRODUCT}

The behaviour of powder materials is influenced not only by the distribution of particle size, but also by the shape and surface structure of the particles forming the powder. A scanning electron microscope (JoelR) was used in this work to view the structure of powder particles. This microscope distributes a stream of electrons onto the powder sample, which was treated by applying a conductive layer to the powder (platinum). The secondarily reflected electrons from the sample surface are captured by a detection equipment and further modified to the form of a digital picture. In Figure 14, the freely sprinkled powder from the pure raw material is illustrated at an enlargement of 150-times. To compare the changes in the structure of the powder, in Figures 15 and 16 broken parts of the product at an enlargement of 1000-times are shown, with various preparation parameters (SED-5.0kV-WD12.3mm-Std.P.C.50.0-HighVacx1000; SED-15.0kV-WD9.9mm-Std.P.C.40.0-HighVac$\mathrm{x} 1000$ ). From the figures, it is clear that the powder has achieved a significant reduction of porosity, the particles were plastically deformed, the number of inter-particle contacts increased, and the particles mutually configured their shape. By this, the product gained a significant strength and became a compact unit.

\section{COMPRESSibility OF PURE RAW MATERIAL AND CREATED PRODUCT}

Not less important investigated data concerns the change in the compressibility of the pure raw material and of the created product. The measuring of compressibility was carried out on a powder materials rheotest, the Freeman Technology FT4 [21-24]. The sample of pure raw material and also the prepared product were compressed by a piston with a very fine perforated surface to allow the escaping of air from the 


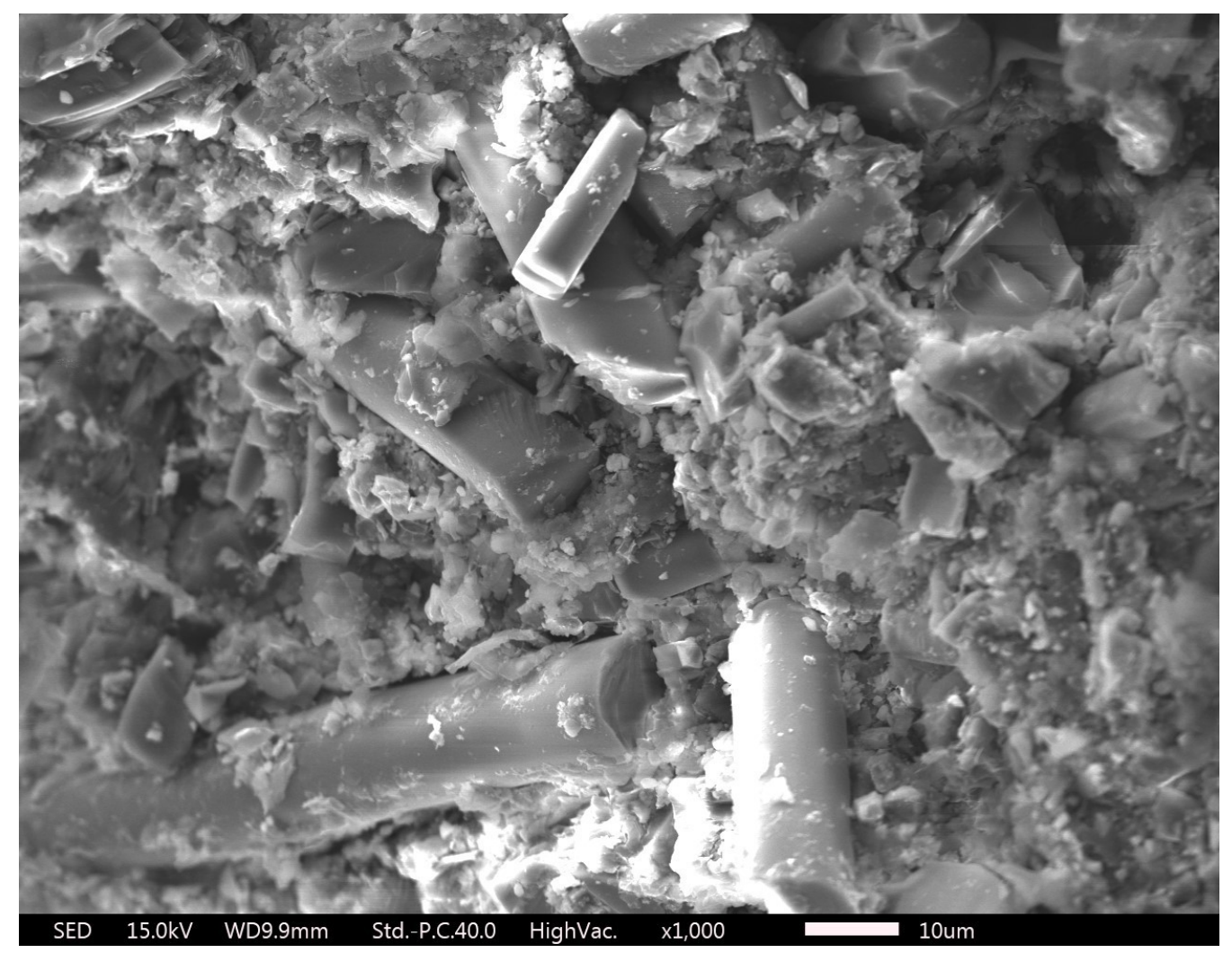

FiguRE 16. Shot of the agglomerate at 1000-times enlargement, made by a JoelR Scanning electron microscope (SED-15.0kV-WD9.9mm-Std.P.C.40.0-HighVac-x1000).

investigated material. The piston applied normalized axial pressure in an interval from 0.5 to $15 \mathrm{kPa}$. A comparison of the compressibility of the pure raw material and the created product is shown in Figure 17

\section{Results And CONCLUSion}

From the measured data of the distribution characteristics, it is clear that while the median size of the pure raw material was $27.8 \mathrm{\mu m}$ (Fig. 12), the one of the created product was $11.24 \mathrm{~mm}$ (Fig. 13). By a suitable setting of the agglomeration process, it was possible to create a sufficiently strongly compacted strip, which, after a subsequent purposed disintegration, provided the required agglomerates. This strength is presented in Figures 9 and 10, we can see an great increase in the strength necessary for the breakage and also for the disintegration of the test sample as a result of the increase of the strength of the forced feeding in the hopper. Such suitably created agglomerates achieved the expected strength, as Figure 17 where it is possible to observe less compressibility (@ $15 \mathrm{kPa}-5.31 \%)$, than in the compaction of the pure raw material powder, which, for the investigated range, was much larger (@15 kPa - 31.5\%). The created agglomerates can be transported right back to the beginning of the production process as a useable recycled material (after the appropriate modification of the size of the particles), since, in terms of a chemical composition, they are made up of a similar composition without the addition of any kind of an agglomerat- ing binder or transport, without the generation of increased dustiness, for material or energy recycling. It should, however, be mentioned that in material recycling, attention must be paid to the fact that such recycled powder has already been compressed many times, leading to a plastic reformation of a number of its components. It is important to discover in what ratio to the pure material the agglomerates can be included in the production process, in order to avoid undesirable lacks of homogeneity in the resultant products (the possibility of a point dislocation of the re-compacted particles after repeated compression in the primary raw material), as well as the possibility of the distribution of individual components of the material, in order to prevent a segregation of fine particles and larger agglomerates (for example silica sand particles), which have significant effects on the brake squeal noise, the evolution of the friction layers and anchoring mechanisms [4].

\section{LIST OF SYMBOLS}

$\alpha_{N}$ Wedge angle $\left[{ }^{\circ}\right]$

$\rho \quad$ Bulk density $\left[\mathrm{kg} \mathrm{m}^{-3}\right]$

$\rho_{\mathrm{o}} \quad$ Initial bulk density $\left[\mathrm{kg} \mathrm{m}^{-3}\right]$

$\rho_{1} \quad$ Material density $\left[\mathrm{kg} \mathrm{m}^{-3}\right]$

$\sigma$ Normal stress [Pa]

$\sigma_{\mathrm{o}}$ Initial normal stress $[\mathrm{Pa}]$

$p_{m}$ Maximum compression pressure $[\mathrm{Pa}]$

$s \quad$ Gap between the rolls [m] 


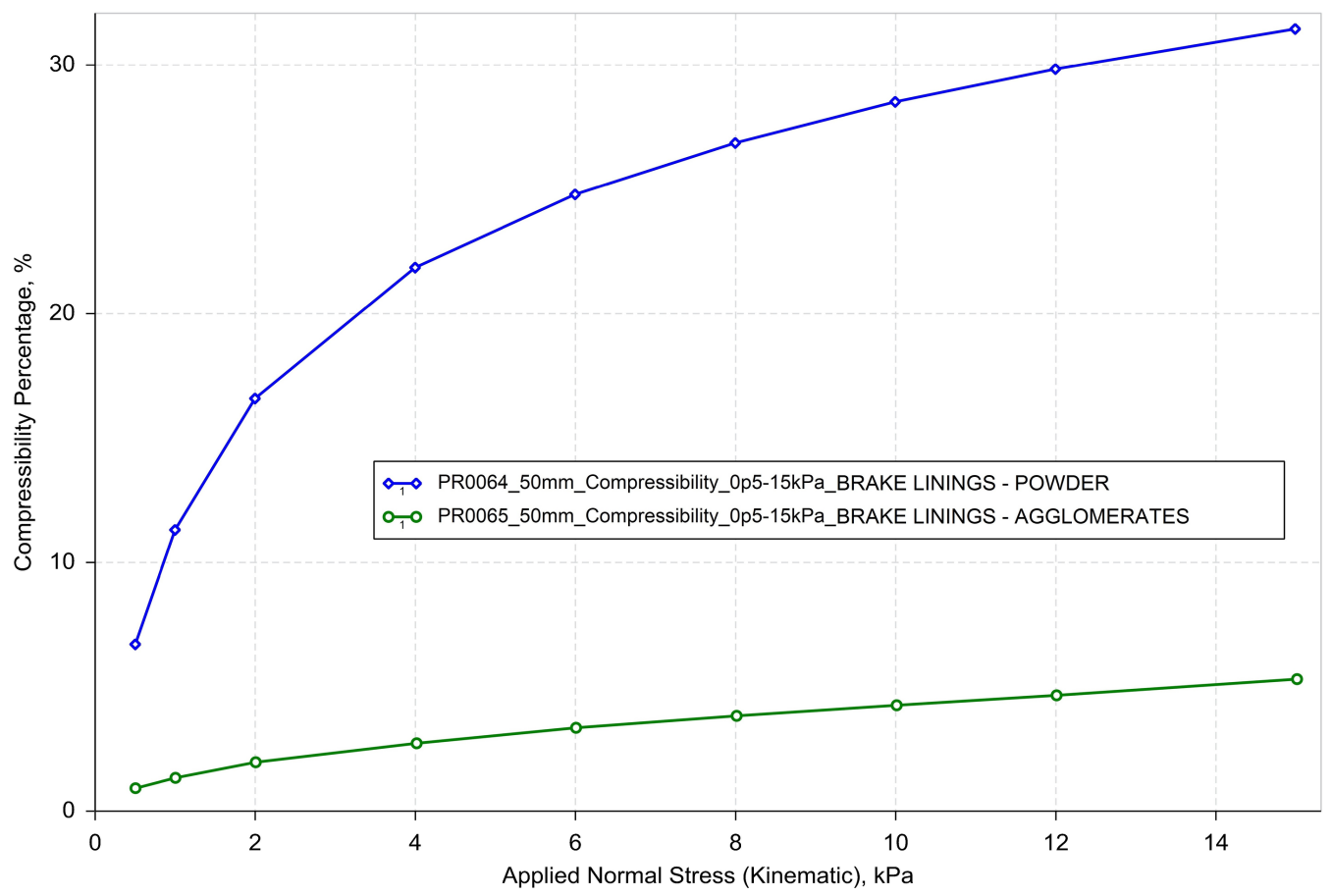

Figure 17. Compressibility of the pure raw material and the created product, measured on Freeman Technology FT4 equipment

$D \quad$ Diameter of the compactor rolls [m]

$K$ Johanson's compressibility factor

\section{ACKNOWLEDGEMENTS}

This article was created with the support of the Ministry of Education, Science, Research and Sport of the Slovak Republic within the Research and Development Operational Programme for the project "University Science Park of STU Bratislava", ITMS 26240220084, co-funded by the European Regional Development Fund.

The authors wish to acknowledge the Scientific Grant Agency of the Ministry of Education, Science, Research and Sport of the Slovak Republic and the Slovak Academy of Sciences for the financial support of this research by grant VEGA 1/0276/17.

This article was created within the grant project "LISPRA" within the program of support for excellent teams of young researchers at the Slovak University of Technology in Bratislava.

This article was created within the grant project "SFEREX" within the program of support for team projects of young researchers at the Slovak University of Technology, Faculty of Mechanical Engineering.

\section{REFERENCES}

[1] M. Baklouti, A. L. Cristol, Y. Desplanques, R. Elleuch. Impact of the glass fibers addition on tribological behavior and braking performances of organic matrix composites for brake lining. Wear 330-331:507-514, 2015. ISSN 0043-1648.

[2] M. C. Lagel, L. Hai, A. Pizzi, et al. Automotive brake pads made with a bioresin matrix. Industrial Crops and Products 85:372-381, 2016. ISSN 0926-6690.

[3] J. Úradníček, P. Kraus, M. Musil. Investigation of frictional stick slip and sprag slip mechanisms leading to disc brake noise vibration and harshness effects. Aplimat 2017 16:1577-1585, 2017. ISBN 978-80-227-4650-2.

[4] A. Mat Lazim, M. Kchaou, M. Abdul Hamid, A. Abu Bakar. Squealing characteristics of worn brake pads due to silica sand embedment into their friction layers. Wear 358-359:123-136, 2016.

[5] L. Francis. Powder Processes (chapter 5). Materials Processing. Academic Press, Boston, 2016. ISBN 9780123851321.

[6] J. R. Johanson. A rolling theory for granular solids. Journal of Applied Mechanics pp. 842-848, 1965.

[7] J. R. Johanson. Factors influencing the design of roll-type briquetting presses. Proceeding of 9-th Biennal Briquetting Conference 9:17-31, 1965. Denver, USA.

[8] J. R. Johanson. Feeding roll presses for stable roll operation. Proceeding of 18-th Biennial Conference of The Institute for Briquetting and Agglomeration 18:209-227, 1983. Colorado Springs, USA.

[9] J. R. Johanson. Fluid entrainment efects in roll press compaction. Powder Handling and Processing 2:183-185, 1989.

[10] J. R. Johanson. Reducing air entrainment problems in your roll press. Powder and Bulk Engineering 43, 1989.

[11] J. R. Johanson. Reducing compacting roll wear through ecient roll face design and operating conditions. Proceeding of 16-th Biennial Conference of the Institute for Briquetting and Agglomeration 16:153-161, 1979. San Diego, Colorado, USA.

[12] A. W. Jenike, R. T. Shield. On the plastic flow of coulomb solids beyond original failure. Journal of Applied Mechanics 26:599-602, 1959. 
[13] K. R. Komarek. Research for wider application of roll presses. Proceeding of 21-thBiennial Conference of The Institute for Briquetting and Agglomeration 21:175-184, 1990. Wood Dale, USA.

[14] A. Krok, R. Fekete, M. Peciar. Compaction of particulate material. STU, Bratislava, 2012. ISBN 978-80-227-3836-1. (In Slovak).

[15] M. Hubert. Application of compresibility equations in the theory of compactor design. Dissertations thesis. STU, Faculty of Mechanical Engineering, Bratislava, 2000. (In Slovak).

[16] M. Hubert, A. Molnar, I. Jasso. Compressibility of particulate matter. Proceeding of 12 th international Congress of Chemical and Process Engineering CHISA 12, 1996. Czech Republic.

[17] M. Peciar, R. Fekete, P. Peciar. Agglomeration technologies of processing powder wastes. Solid State Phenomena 244:121-129, 2016. ISSN 1012-0394.

[18] D. Geldart, E. Abdullah, A. Verlinden. Characterisation of dry powders. Powder Technology 190:70-74, 2009.

[19] U. Ulusoy, I. Kursun. Comparison of different 2D image analysis measurement techniques for the shape of talc particles produced by different media milling. Minerals Engineering 24:91-97, 2011.

[20] C. Vevoguer. Using laser diffraction to measure particle size and distribution. Metal Powder Report 68:15-18, 2013.

[21] R. Freeman. Measuring the flow properties of consolidated, conditioned and aerated powders - a comparative study using a powder rheometer and a rotational shear cell. Powder Technology 174:25-33, 2007.

[22] R. Freeman, J. R. Cooke, L. Schneider. Measuring shear properties and normal stresses generated within a rotational shear cell for consolidated and non-consolidated powders. Powder Technology 190:65-69, 2009.

[23] L. Grossmann, J. Tomas, B. Csoke. Compressibility and flow properties of a cohesive limestone powder in a medium pressure range. Granullar Matter 6:103-109, 2004.

[24] G. Lumay, F. Boschini, K. Traina, et al. Measuring the flowing properties of powders and grains. Powder Technology 224:16-27, 2012. 